\title{
Brain injury in children and adolescents
}

\author{
Judith A. Middleton
}

Acquired brain damage in children is not uncommon, head injuries being the most frequent cause. Brain injury may also occur during the very vulnerable periods of rapid growth of the foetal brain from prenatal trauma/strokes, during a difficult birth, or postnatally from strokes, infections (e.g. meningitis and encephalitis), metabolic disturbances (e.g. phenylketonuria), treatment (e.g. central nervous system (CNS) surgery or radiotherapy for leukaemia) or toxins (e.g. alcohol and valproate). This paper concentrates on the assessment of and interventions following acquired brain injury sustained after the first 2 years of life, that is, after a period of relatively normal development when there has been an expectation that a child will follow the usual trajectory in development and learning throughout childhood and adolescence. Acquired brain injury in younger children tends to have global and profound effects, for instance, from CNS radiation (Said et al, 1989) or head injury (Levin et al, 1995). Injury in older children may result in more specific or focal problems depending on the mechanism of injury.

\section{Presenting problems}

What will mark out children with acquired brain injury from those who have had learning difficulties from birth is the presentation of reported change in cognition, behaviour, emotion or personality. Such changes may be subtle, although they can be dramatic. After a period of rapid recovery from a head injury over a matter of days, weeks or months, families and teachers may report that what seemed at first to be relatively minor problems or adjustment difficulties on return to everyday life at home and in the school have grown in significance. There may be no outward sign that the child has received major trauma to the brain and problems initially may be considered to have arisen from the psychological trauma of the injury or illness, time in hospital and consequently away from home and school, part of the general recovery process following injury or illness, or a change in the parents' or school's handling of the child. Each of these could indeed partly explain the perceived change in the child, but there may be specific difficulties arising from damage to the brain (Goodman, 1994). Children who receive radiotherapy for leukaemia can show a slowly emerging pattern of deficits (Anderson et al, 1994).

As the main aim of this paper is to describe how clinicians in child and adolescent mental health can help these children and their families, the specific problems arising from acquired brain injury will be described only briefly and the reader is referred to more extensive sources on head injury (Broman \& Michel, 1995), treatment effects of leukaemia (Anderson et al, 1994) and brain tumours (Dennis et al, 1991). However, before any interventions can be considered, an assessment of the full complexity of difficulties including the injury variables (cause, severity and type of injury) and child variables (premorbid functioning and behaviour and age and developmental level; see Middleton (2001) for a fuller discussion) is needed.

\section{The child with traumatic brain damage}

The problems following injury can be considered in relation to behavioural, emotional, cognitive and physical functioning.

Judith Middleton is aconsultant clinical psychologist at the Radcliffe Infirmary (Oxford, OX2 6HE), where she specialises in child neuropsychology and works with children with cranio-facial disfigurement. She set up and ran for 4 years a course for the British Psychological Society on child clinical neuropsychology, and has lectured extensively on clinical training courses. 


\section{Behavioural difficulties}

Behavioural difficulties are often the problem that prompts a referral. Work by Brown et al (1981) indicated that children with severe head injury (severe defined as post-traumatic amnesia (PTA) of more than 7 days' duration) were three times more likely to present with novel psychiatric disturbance compared with premorbid functioning, but new problems did not arise in mildly injured children (PTA for less than 7 days) and an orthopaedic control group. On the other hand, children with mild head injury were more likely to have had premorbid emotional and behavioural problems than the group with severe head injury and control group. Similar findings in the USA by Max et al (1998a) have also shown that psychiatric problems are more likely to emerge after severe than after mild head injury. The most common problems include the following.

- Impulsive behaviour leading to accidents, untidy work, etc. can result in an increased supervisory role for parents and concerns that they have to be constantly vigilant.

- Poor attention and concentration, which may be mistaken for attention-seeking behaviour, can be a persistent.

- Increased irritability, anger and temper tantrums may occur. Children may be described as having a very short fuse. Max et al (1998a) found that oppositional defiant disorder symptomology in the first year post-injury is often linked to social class and pre-injury problems and family functioning, but may be associated with severity of injury 2 years after the event.

- Disinhibited behaviour may be shown, which can be verbal, physical and, very occasionally, sexual. Brown et al (1981) found that children with severe head injuries (but not the mild injury or control groups) developed a disinhibited state. Of all presenting problems, disinhibition may be considered that most specifically related to traumatic brain injury, although Brown et al found only a modest positive dose-response relationship. Of all the behavioural problems, it is disinhibition that often causes most concern to families and teachers alike.

- Lethargy and inertia is common. Not all children present with the positive signs described above: some become difficult to interest in anything and seem to have lost all 'get up and go', sitting around all day, having been active and full of energy in the past.

With the possible exception of disinhibition, none of these difficulties is exclusively the domain of acquired brain injury. However, even if problems were present prior to the injury, and there is evidence that children with head injuries, for instance, are a self-selecting group, it is the change in the frequency, duration and intensity of the problems that is striking and that may bring about a referral.

\section{Emotional problems}

Emotional problems should not be overlooked, although they can be masked by difficult behaviour, and a referral may be made for a number of reasons, among them the following.

- Depression may arise from the perceived and real losses that have resulted from injury (e.g. loss of academic status and future career aspirations; loss of status in the family perhaps a younger sibling is now more able and more competent; loss of friendships; and difficulty in making new friends, resulting in loneliness). In addition, acquired physical impairments, even if relatively minor, can have a major impact on a child's self-worth and can also, for example, lead to exclusion from teams or playground activities because physcial skills have deteriorated. Scarring may appear stigmatising and even minor disfigurement can be a major problem for self-image (Kish \& Lansdown, 2000). Loss of fertility resulting from treatment (e.g. after intensive radiotherapy for leukaemia or brain tumours) may also be an issue.

- Children who have suffered life-threatening illness may fear the recurrence of the illness and subsequent death.

- Anxiety may be less obvious, but is often related to loss of skills and to children feeling that they are less able to cope with school or life in general, against a background where they are expected to catch up and keep up with their school work and live up to parental and school expectations.

- Post-traumatic stress disorder (PTSD) needs to be considered, even if there is a report of a short loss of consciousness. Failure to have a continuous memory of events does not exclude the development of PTSD (McMillan, 1996). Memory of the approaching vehicle in a road traffic accident, being cut out of a vehicle by the emergency services or seeing other people who have been injured or killed may be present.

- Grief is perhaps less common, but where an accident involves significant others, the resulting death of a parent, sibling or friend may cause a sense of acute loss, changed home circumstances and feelings of survivor guilt. 


\section{Cognitive problems}

Cognitive problems may include any or all of the following.

- Reduced speed of processing of visual and verbal information, longer thinking time and slower motor or verbal responses are common. Children are usually slower than they were before an injury, particularly after severe injury (Bawden et al, 1985). This can have an enormous impact on daily living skills, safety, particularly in complex, noisy and fast-moving environments, social relationships and educational achievement.

- Poor attention and concentration and high distractability are among the most common complaints of parents and teachers, with concerns about their impact on learning and safety (Dennis et al, 1995).

- Visuo-perceptual and spatial problems may present as untidy work or a decline in writing and drawing ability, or there may be major problems acquiring these skills; there may also be impaired constructional skills, or poor skills in sports and gymnastics.

- Memory and learning problems may occur, particularly in the ability to learn and retain new information, to integrate this into the existing knowledge base and to generalise what has been learnt to new situations (Levin et al, 1995).

- Higher-level language difficulties are not always obvious, but children may find processing complex and abstract ideas, making inferences or understanding ambiguity a problem (Chapman, 1995).

- Problems with executive skills are not uncommon, including goal-setting, systematic planning and initiating, organising and executing plans to reach the desired goal. There may be difficulties in evaluating the viability of goals and monitoring progress and goal attainment (see Dennis, 1991).

Presentation of any of these difficulties may not be immediately obvious, as parents and schools often observe underachievement and a failure to make progress post-injury. Referral may not occur immediately after an injury. Indeed, it can take time for the effects of these problems to become apparent. It may be 2 or 3 years after the injury before serious concerns arise. If the child is young at injury (under the age of 3 or 4 years), problems may be more global than specific. In addition, as the brain is still developing during the first two decades, some problems directly related to the injury may not surface until those areas of the brain that have been damaged are fully mature (e.g. the frontal lobes).

\section{Physical impairments}

Physical impairments arising from acquired brain injury have been mentioned in passing in the above sections but need to be considered separately within a thorough assessment. Although many children suffering from acquired brain injury do not have these difficulties, epilepsy, subtle visual problems, field defects, hearing loss, tremor, weakness, sensory loss, loss of bladder control and increased tiredness can occur (Hall et al, 1990). Where they are present, they have a significant impact on children's psychological, social and academic functioning, as well as on how they feel about themselves. An emotional response and difficult behaviour arising from these losses or problems may be most usefully seen as a normal reaction to new circumstances rather than as a psychopathological problem.

\section{Interaction of impairments}

It should be clear from what has been described that problems following acquired brain injury are rarely discrete. Pre-existing difficulties and the injury variables will also need to be considered in understanding the presenting problems. Cognitive, behavioural, emotional and physical problems arising directly and indirectly from acquired brain injury frequently interact in a complex way. That a number of these problems may have been present prior to injury should not in itself automatically lead to the erroneous conclusion that the effect of the injury has been minimal, as premorbid difficulties can be exacerbated (Donders \& Strom, 1997). Again, it is the reported change that is critical, and many problems that were present but manageable before the injury can become a major source of concern.

\section{Families of children with acquired brain injury}

Before considering effective interventions in more detail, it is important to review the effect of injury on families. Head injury in children (and in adults) always has considerable implications for the family and no adequate intervention can ignore their impact. Parents may themselves experience a wide variety of difficulties, including the following. 
- They may feel guilty if they have been in part responsible for an accident (i.e. as the driver of a car), or experience perceived guilt if they feel they should have done more to protect their child. Some parents feel that a serious illness would have been detected and treated sooner had they been more vigilant.

- Blame towards a spouse or partner who has caused the injury directly, for example, in a non-accidental injury or through driving carelessly, or indirectly, perhaps by not giving adequate supervision, can be destructive in an already vulnerable situation.

- PTSD may be experienced. Some families witness their child's accident even if they are not directly implicated in it, and they have vivid memories of seeing their child lying in the road, or in intensive care.

- Depression and despair about being unable to cope with a difficult child may occur, as well as anxieties about the future.

- A sense of helplessness can be compounded by a feeling of not knowing enough about the mechanisms of injury and about what can be done, where to get help and how to access it.

- There may be feelings of anger towards those 'responsible' for the injury - the driver of the vehicle, the school for not giving adequate supervision, or health care staff if diagnosis and treatment of a major illness appears to have been slow.

- Hopelessness can also arise from feeling unable to manage a difficult child, when parents had previously considered themselves competent. If there are now major physical problems, parents may become excessively tired, having to take a more active role in the physical care of their child.

- Both fear and relief that their child has recovered can lead to a change in management and handling of behaviour, and the child may be overprotected and indulged in a way that did not occur before (Gaidolfi \& Vignolo, 1980). This can lead other siblings to accuse parents of unfairness.

- Sometimes, one or both parents feel it necessary to give up work following the injury, and this can dramatically change the financial situation, leading to tensions within the family that may have a direct effect on the siblings and on child care.

It is also important to consider the effect on siblings and how the sequelae of the injury to one child might affect the lives of members of the extended family. Parents may believe that siblings are relatively unaffected, but other children in the family may become protective of their parents and say nothing, while quietly harbouring a sense of loss and anxiety, as well anger and guilt about their anger (Middleton, 1997). A change in the family structure, when younger siblings appear to take on a quasi-supervisory and adult role in the care of the injured child, may superficially appear adaptive, but can be destructive in the long term. In the end, resentment towards the injured sibling may lead to open hostility and family friction, or feigned indifference.

Any intervention in the problems following acquired brain injury to a child should include a comprehensive assessment of all the issues discussed above. This means that initial assessment may need to be carried out within an interdisciplinary team (Semlyen et al, 1998). A team approach is often needed in planning effective interventions, and although such an approach may not directly affect the natural process of recovery it can considerably reduce carer stress (Semlyen et al, 1998).

The diagram in Fig. 1 illustrates the many contributory factors affecting a boy with a severe head injury, described in the following case study.

\section{Case study}

This is a hypothetical, although not unrealistic, case where referral is made following angry outbursts that are getting out of control. G is a boy of 12 years presenting 4 years after a serious road accident, when he was knocked unconscious for 24 hours following a cycling accident involving a car, resulting in diffuse axonal and temporary speech problems and a very mild right-sided weakness. Prior to the accident, he was popular in school but was seen to have attentional problems. Following the injury, he made a relatively good recovery, at least superficially, but was left with slow information processing, poor attention and concentration, impulsive behaviour, distractability, subtle higher-level language problems and poor organisational skills. These difficulties were relatively well-contained in his primary school, where his history was known, and were not seen serious enough to warrant help beyond Level 1 in the Code of Practice. He generally maintained his friendships by playing the class clown.

During the period that followed the injury, there were major changes in the family's home life. G's father had been cycling with him when the accident occurred, and, although there was negligence by the driver, his mother had blamed her husband for not taking sufficient care of G. G had been born some time after the other children and was a particularly precious child in whom his parents had high hopes of academic success. Because of the need for constant supervision in the early days after the injury, G's 


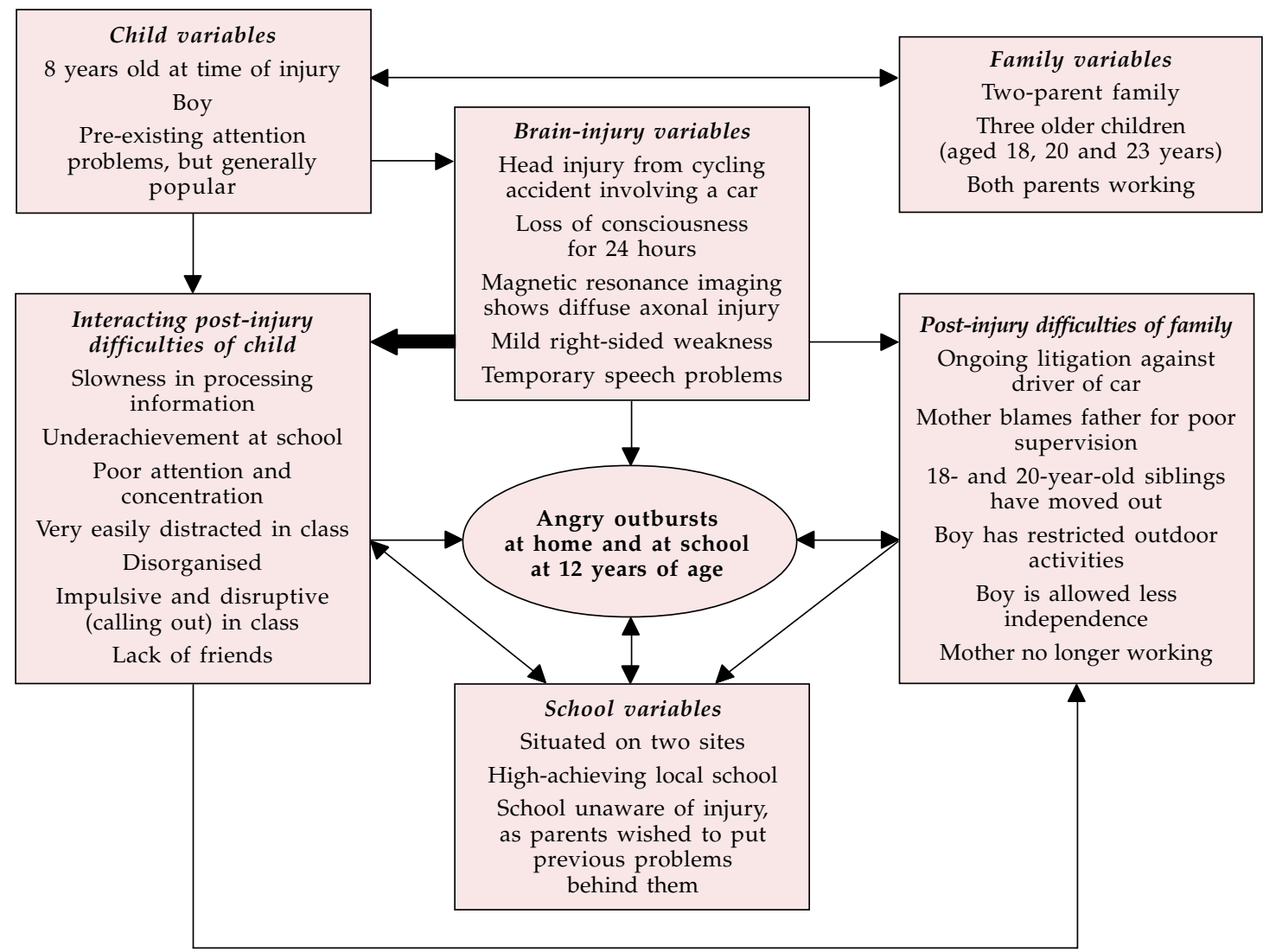

Fig. 1 A simplified diagram showing different variables contributing to difficult behaviour

mother gave up work, which added to her anger about what had happened, created some financial difficulties and resulted in general anxiety and increased grief. Because of the resultant tensions at home, both the middle children moved out earlier than had been anticipated, thus reducing the amount of support their mother received in keeping an eye on G.

Because of reasonable progress and containment in primary school, when G's parents arranged his secondary school transfer, they decided they would put the past behind them and did not inform his new school of his injury. However, in secondary school G had to cope with the need for much greater independence in organising himself, a fast-moving school environment, where he had to get from one classroom to another - sometimes on different sites - and an expectation that the majority of children would finally be attaining reasonable GCSE grades. G's behaviour in the classroom, which had been tolerated in primary school, was now reprimanded. His old friends fell away from him and he found it difficult to make new ones. Consequently, he began failing in school, frequently being told off and becoming isolated. Because his mother continued to be concerned about him, she restricted his independence compared with other children in his class and this caused anger at home, where she was seen as unreasonable. Her old concerns and anger had not been dealt with and were exacerbated by the ongoing litigation against the driver of the car, which was a constant reminder of the accident. G's father rarely spoke of the accident, although he continued to have vivid memories of his son lying under the car. His wife found his silence about the accident difficult to cope with.

This hypothetical case, based on the cases of many children seen over the years, is certainly not uncommon. It illustrates that in dealing with a child presenting with conduct problems, or what might be classified as oppositional defiant disorder, following an accident, the direct sequelae of the brain damage interact with pre-existing child, family and school variables. 


\section{What can be done?}

The importance of a thorough assessment of all aspects of the brain injury is essential, and it may well be that formal referral to a child clinical neuropsychologist, physiotherapist, occupational therapist and speech and language therapist is required in order to ascertain a full understanding of the child's problems. It follows that an interdisciplinary approach towards intervention is highly desirable. However, there are few areas where a fully integrated approach is available, and this in itself can create anger, anxiety and despair in parents. The following interventions should be considered.

\section{Explanation and information}

Many parents do not fully understand the mechanisms of brain injury nor how it directly affects behaviour, even after a period of good recovery. There may be false beliefs, for example, that if only there were more therapy, etc. their child would make a full recovery. Consequently, accessible and realistic information about the injury can be helpful (Waaland et al, 1993) and this may need to be revisited at different times. Children themselves may also need to be given an explanation at an appropriate developmental level, as they are often ignorant of the variety of issues surrounding the effect of their brain injury (Jacobs, 1993).

In addition, discussing the dynamics of the injury's effects on family functioning and how the accident may have indirectly affected other members of the family, for example, difficult siblings, is a useful start in planning interventions, not just for the child, but for other family members.

Finally, many families will need assistance and information on how to get help for their child, particularly in establishing appropriate education, which is often a long-term source of anxiety and stress.

\section{Adaptation}

Clear explanation and information may enable schools, families and children to be realistic about present and future expectations. If there is a belief that more therapy and extra tuition will lead to full recovery, children can be put under considerable stress by being expected to work to catch up, making them more tired, irritable and, finally, defiant or depressed, as shown in the following case vignette.
After a head injury, H (18 years) worked every evening, weekend and throughout the holidays to achieve A levels of a sufficient standard to get into university, although he would have sailed through these before his accident. This was at the expense of peer and social contact, which led to feelings of isolation, frustration and disappointment when he still failed to get the expected grades.

Children may present with many problems, but those with conduct or attention-deficit disorder may particularly benefit from adaptations to the school curriculum if part of the aetiology of their difficulties results in an inability to cope with the amount and complexity of work. Similarly, even relatively small physical adaptations to equipment at home and the provision and simplification of worksheets at school, for instance, can reduce failure and frustration.

\section{Cognitive and behavioural strategies}

Families

The types of problem listed above may leave many parents feeling that they are unable to cope and to deal with their child. Max et al (1998a) found premorbid family coping strategies and family dysfunction to be important factors in the aetiology of post-injury psychiatric problems in children. Early interventions can be especially beneficial. At a basic level, behavioural management strategies may help parents to set boundaries (McGuire \& Rothenberg, 1986) that they have found difficult to consider before, feeling that their child has suffered enough and should be given licence to behave at will. Behavioural management techniques carried out in a consistent way from the very early stages of recovery may lead to a reduction in problems where medication has failed (McGuire \& Rothenberg, 1986).

Second, advice on how to cope with attention, memory and executive difficulties, which may indirectly give rise to difficult behavioural problems, can be very helpful. Articulating the informationprocessing difficulties that may contribute to defiant behaviour (e.g. being able to retain only one instruction at a time and not understanding complex language) can enable parents to use simple rehabilitation strategies so that the child is successful and they feel themselves to be effective parents.

\section{Children}

There are numerous strategies that children can use in order to manage problems arising from brain 
injury. Early behavioural management interventions in the acute phase may prevent early disruption to therapy and recovery and forestall later problems (Slifer et al, 1993). Use of rehabilitation strategies for problems with organisation, memory and language (Ylvisaker et al, 1998b) and executive functions (Ylvisaker et al, 1998c) can be effective. For example, external aids for memory problems include the use of diaries, note-books and electronic reminders. In addition, introducing and teaching the consistent use of strategies in the organisation of tasks such as dressing to completing a homework project can result in improved performance and, in turn, enhanced self-esteem.

\section{Schools}

Intervention in school can dramatically change children's success and subsequent behaviour. The use of simple rehabilitation strategies can be effective in changing what appear to be intractable problems in managing a child in the classroom.

\section{Individual treatment}

\section{Parents}

Parents may need time, understanding and licence to acknowledge their fears, anger and anxiety within a safe setting. As there may have been premorbid psychiatric problems (Max et al, 1998a) appropriate cognitive-behavioural work with individual family members might alleviate anxiety, depression and PTSD, as might medication. Family sessions can allow quiescent but intense responses to the injury to be aired in a contained environment. It is also important to normalise emotional reactions to the injury, and to acknowledge that the injury has changed family life, sometimes dramatically.

\section{Children}

Where it is appropriate, children who have been injured need to talk about their own reaction to the injury, their anxieties and fears for the future and possible depression at the independence and future hopes they may have lost (McCabe \& Green, 1987). Psychological therapies for PTSD can be very effective (Perrin et al, 2000). Cognitive-behavioural interventions to deal with anger management and anxiety are also useful (Ylvisaker et al, 1998a). Social skills groups can help in dealing with peer relationship problems.

Epilepsy may need medical intervention and parents and children need to understand the sideeffects of medication.
Attention-deficit hyperactivity disorder is a common sequela of injury and there have been successful interventions with children with head injury using the usual range of medications (Hornyak et al, 1997; Parmelee \& O'Shanick, 1987). Stimulants are also reported to have been effective in children with lethargy (Hornyak et al, 1997).

\section{Self-help groups}

It is important to put children and families in touch with national and local support groups. For example, the Children's Brain Injury Trust, Headway and the Meningitis Trust support families and individuals who have suffered brain injury and they have written useful, accessible information across a wide range of relevant issues.

\section{Coordinating rehabilitation}

Where there are multiple problems leading to the involvement of a number of different health and education staff working with one family, it is important that service delivery is coordinated. Depending on the major issues, any one of a number of senior clinicians from different disciplines may be the most appropriate person to act as coordinator for a particular child. As children make progress, it is possible that there is a change of coordinator depending on the issues that are important at the time.

\section{Summary and conclusions}

It is very rare that a simple formulation and intervention are sufficient to help children with acquired brain injury. This paper reviews the kinds of questions and issues that need to be addressed and describes the types of therapeutic intervention that can be effective in alleviating problems.

\section{References}

Anderson, V., Smibert, E., Ekert, H., et al (1994) Intellectual, educational, and behavioural sequelae after cranial irradiation and chemotherapy. Archives of Disease in Childhood, 70, 476-483.

Bawden, H. N., Knights, R. M. \& Winogren, H. W. (1985) Speeded performance following head injury in children. Journal of Clinical and Experimental Neuropsychology, 7, 3954.

Broman, S. H. \& Michel, M. E. (eds) (1995) Traumatic Brain Injury in Children. Oxford: Oxford University Press. 
Brown, G., Chadwick, O., Shaffer, D., et al (1981) A prospective study of children with head injury: III Psychiatric sequelae. Psychological Medicine, 11, 49-61.

Chapman, S. B. (1995) Discourse as an outcome measure in pediatric head-injured populations. In Traumatic Brain Injury in Children (eds S. H. Broman \& M. E. Michel), pp. 95-116. Oxford: Oxford University Press.

Dennis, M. (1991) Frontal lobe function in childhood and adolescence: a heuristic for assessing attention regulation, executive control, and the intentional states important for social discourse. Developmental Neuropsychology, 7, 327-358.

_ , Spiegler, B. J., Hoffman, H. J., et al (1991) Brain tumours in children and adolescents - I. Effects on working, associative and serial-order memory of IQ, age at tumor onset and age of tumor. Neuropsychologia, 29, 813-827.

- Wilkinson, M., Koski, L., et al (1995) Attention deficits in the long term after childhood head injury. In Traumatic Brain Injury in Children (eds S. H. Broman \& M. E. Michel), pp. 165-187. Oxford: Oxford University Press.

Donders, J. \& Strom, D. (1997) The effect of traumatic brain injury on childen with learning disability. Pediatric Rehabilitation, 1, 179-184.

Gaidolfi, E. \& Vignolo, L. A. (1980) Closed head injuries in school aged children: neuropsychological sequelae in early adulthood. Italian Journal of Neurological Science, 1, 65-73.

Goodman, R. (1994) Brain disorders. In Child and Adolescent Psychiatry: Modern Approaches (eds M. Rutter, E. Taylor \& L. Hersov), pp. 172-190. Oxford: Blackwell Scientific Publications.

Hall, D. M. B., Jones, S. L. J. \& Middleton, J. A. (1990) Rehabilitation of head injured children. Archives of Disease in Childhood, 65, 553-556.

Hornyak, J. E., Nelson, V. S. \& Hurvitz, E. A. (1997) The use of methylphenidate in paediatric traumatic brain injury. Pediatric Rehabilitation, 1, 15-17.

Jacobs, M. P. (1993) Limited understanding of deficit in children with brain dysfunction. Neuropsychological Rehabilitation, 3, 341-365.

Kish, V. \& Lansdown, R. (2000) Meeting the psychological impact of facial disfigurement: developing a clinical service for children and families. Clinical Child Psychology and Psychiatry, 5, 497-512.

Levin, H. S., Ewing-Cobbs, L. \& Eisenberg, H. M. (1995) Neurobehavioral outcome in pediatric closed head injury. In Traumatic Brain Injury in Children (eds S. H. Broman \& M. E. Michel), pp. 70-94. Oxford: Oxford University Press.

Max, J. E., Robin, D. A., Lindgren, S. D., et al (1997) Traumatic brain injury in children and adolescents: psychiatric disorder at two years. Journal of the American Academy of Child and Adolescent Psychiatry, 36, 1278-1285.

- Castillo, C. S., Bokura, H., et al (1998a) Oppositional defiant symptomatology after traumatic brain injury: a prospective study. Journal of Nervous and Mental Diseases, 186, 325-333.

_ - Robin, D. A., et al (1998b) Predictors of family functioning after traumatic brain injury in children and adolescents. Journal of the American Academy of Child and Adolescent Psychiatry, 37, 83-90.

McCabe, R. J. R. \& Green, D. (1987) Rehabilitation of severely head-injured adolescents: three case reports. Journal of Child Psychology and Psychiatry, 28, 111-126.

McGuire, T. L. \& Rothenberg, M. B. (1986) Behavorial and psychological sequelae of pediatric head injury. Journal of Head Trauma Rehabilitation, 1, 1-6.

McMillan, T. (1996) Post-traumatic stress disorder following minor and severe closed head injury: 10 single cases. Brain Injury, 10, 749-758.

Middleton, J. A. (1997) You're Not the Only One: Having a Brother or Sister with a Head Injury. Oxford: Oxford University Press.

- (2001) Practioner review: psychological sequelae of head injury in children and adolescents. Journal of Child Psychology and Psychiatry, 42, 165-180.

Parmelee, D. X. \& O'Shanick, M. D. (1987) Neuropsychiatric interventions with head injured children and adolescents. Brain Injury, 1, 41-47.
Perrin, S., Smith, P. \& Yule, W. (2000) The assessment and treatment of post-traumatic stress disorder in children and adolescents. Journal of Child Psychology and Psychiatry, 41, 277-290.

Said, J. A., Waters, B. G., Cousens, P., et al (1989) Neuropsychological sequelae of central nervous system prophylaxis in survivors of childhood acute lymphoblastic leukaemia. Journal of Consulting and Clinical Psychology, 57, 251-256

Semlyen, J. K., Summers, S. J. \& Barnes, M. P. (1998) Traumatic brain injury: efficacy of multidisciplinary rehabilitation. Archives of Physical Medicine and Rehabilitation, 78, 678-683.

Slifer, K. J., Cataldo, M. D., Babbitt, R. L., et al (1993) Behavior analysis and intervention during hospitalisation for brain trauma rehabilitation. Archives of Physical and Medical Rehabilitation, 74, 810-817.

Waaland, P. K., Burns, C. \& Cockrell, J. (1993) Evaluation of needs of high- and low-income families following paediatric traumatic brain injury. Brain Injury, 7, 135146.

Ylvisaker, M., Feeney, T. J. \& Szekeres, S. F. (1998a) Socialenvironmental approach to communication and behavior In Traumatic Brain Injury Rehabilitation: Children and Adolescents (2nd edn) (ed. M. Ylvisaker), pp. 271-302. Oxford: Butterworth-Heinemann.

- Szekeres, S. F., \& Haarbauer-Krupa, J. (1998b) Cognitive rehabilitation: organisation, memory and language. In Traumatic Brain Injury Rehabilitation: Children and Adolescents (2nd edn) (ed. M. Ylvisaker), pp. 181-220. Oxford: Butterworth-Heinemann.

,,-- \& Feeney, T. J. (1998c) Cognitive rehabilitation: executive functions. In Traumatic Brain Injury Rehabilitation: Children and Adolescents (2nd edn) (ed. M. Ylvisaker), pp. 221-270. Oxford: Butterworth-Heinemann.

\section{Multiple choice questions}

1. The most vulnerable group of children, suffering the worst prognosis after acquired brain injury, are:

a infants

b children in middle childhood

c children in later childhood

$\mathrm{d}$ adolescents.

2. The most common cognitive problem arising from brain injury in childhood and adolescence affects:
a visuo-spatial functioning
$\mathrm{b}$ attention and concentration
c reading
d verbal comprehension.

3. Acquired brain injury in childhood affects:
a the index child
b siblings
c parents
d peer relationships.

4. Behavioural and emotional problems that are exclusive to head injury are:

a depression 
b conduct disorder

c attention-deficit dirorder

d disinhibition.

5. Problems arising from acquired brain injury may emerge:

a immediately after injury

b within 3 months

c within 1 year

d up to $4-5$ years after injury.

MCQ answers

$\begin{array}{llllll}1 & 2 & 3 & 4 & 5\end{array}$

a $T$ a $F$ a $T$ a $F$ a $T$

b $\begin{array}{llllll} & \text { b } T & \text { b } T & \text { b } F & \text { b } T\end{array}$

c $F$ c $F$ c $T$ c $F$ c $T$

$\begin{array}{llllll}\text { d F } & \text { d F } & \text { d } T & \text { d } T & \text { d } T\end{array}$

\section{The Royal College of Psychiatrists Conferences in 2001}

Annual Meeting

9-13 July 2001

QEII Centre, London

Joint Meeting of Philosophy and WPA Section

14 July 2001

SOAS, London

Annual Residential Meeting of the Child and Adolescent Psychiatry Faculty

3-5 October 2001

University of York

Faculty for the Psychiatry of Learning Disability Residential Meeting

10-12 October 2001

Jarvis Hotel, Chester

Section of Rehabilitation and Social Psychiatry Residential Meeting

15-16 November 2001

Gosforth Marriott Hotel, Newcastle

Fitness to Drive (Old Age Psychiatry)

5 December 2001

$\mathrm{SCl}$, London

For further information please contact:

Conference Office, Royal College of Psychiatrists, 17 Belgrave Square, London, SW1X 8PG.

Tel: +44 (0)2072352351 Ext 142 Fax: +44 (0)20 72451231 Website: www.rcpsych.ac.uk 